\title{
Using Open-Source Data to Study Bias Homicide Against Homeless Persons
}

\author{
Jeffrey A. Gruenewald ${ }^{*}$
}

University of Arkansas, USA

\begin{abstract}
Despite their high-profile nature, there has been a lack of scholarly research on bias-motivated homicide in the United States. One explanation for this dearth of prior research is the lack of official data available on this type of crime. In response, the current study proposes an alternative method for studying one form of bias crime, homicides targeting homeless persons, using open-source data (e.g., court documents, news media reports, advocacy group chronologies, etc.). To demonstrate their utility, open-source data are employed to empirically examine anti-homeless homicide incident, suspect, and victim characteristics. Findings reveal that anti-homeless homicide tends to be committed in public parks with blunt objects by groups of young males against older, solitary male victims. Implications for policy are briefly discussed.
\end{abstract}

Keywords: Homicide, homelessness, open-source data.

\section{INTRODUCTION}

Every year people are killed because of who they are and what they represent. Some are targeted because they are gay, Black, Jewish, or like the victims of interest to this study, homeless. It is commonly left up to journalistic accounts to inform the public about bias-motivated attacks. Criminologists have largely ignored these crimes, which are viewed as aberrations to more prevalent types of homicide in the United States. Undoubtedly, bias homicide occurs less frequently than other types of lethal violence, such as argument-related homicide (see Cooper \& Smith, 2011). Importantly, though, failing to empirically examine these serious crimes is to the detriment of our understanding of fatal violence in general and bias homicide in particular. It cannot simply be assumed that the same patterns which underlie commonly occurring deadly encounters also exist for bias homicide. Other reasons for criminologists not to ignore homicide against minority groups include the potential for increased harm to victims' communities caused by discriminatory violence. There is also potential for these cases to influence public opinion and shape the discourse regarding additional legal protections for minority groups. One explanation for the lack of empirical attention to such homicides is the absence of available official data on these crimes. Whereas most homicide studies rely on police data, such data on bias homicide is currently lacking in the United States. The current study addresses this and other methodological obstacles by suggesting that one alternative option to relying on official data is the use of open-source data

*Address correspondence to this author at the University of Arkansas, USA; Tel: 479-575-2057; E-mail: jgruenew@uark.edu for studying the extent and nature of bias homicide, specifically those events targeting homeless persons.

This research contributes to the study of violence against homeless persons by focusing on homicides that have occurred across the United States. Data on anti-homeless homicide from 1999 to 2009 in the United States are extracted from an open-source database on extremist violence, known as the Extremist Crime Database (ECDB). ${ }^{1}$ The ECDB includes data for bias homicide cases involving victims who were discriminately targeted because of their statuses as homeless persons, hereafter referred to as "anti-homeless homicide." Based on these data, an exploratory analysis of incident, victim, and offender characteristics is conducted to describe the nature of these lethal attacks. In short, the current study has a dual purpose, including: 1) demonstrating the utility of open-source databases as an alternative (or supplementary) data source for studying relatively rare forms of bias homicide and 2) exploring the nature of anti-homeless homicide. Accordingly, the current study unfolds in the following way. To begin, methodological obstacles to studying bias homicide and other rare forms of lethal violence are discussed. Then, in response to such obstacles, the advantages and disadvantages of open-source criminal events data are presented. Next, a brief discussion of lethal violence against homeless persons as one form of bias homicide is provided. In addition, a discussion of the open-source methodology utilized in the current study is then provided along with descriptive results from an 


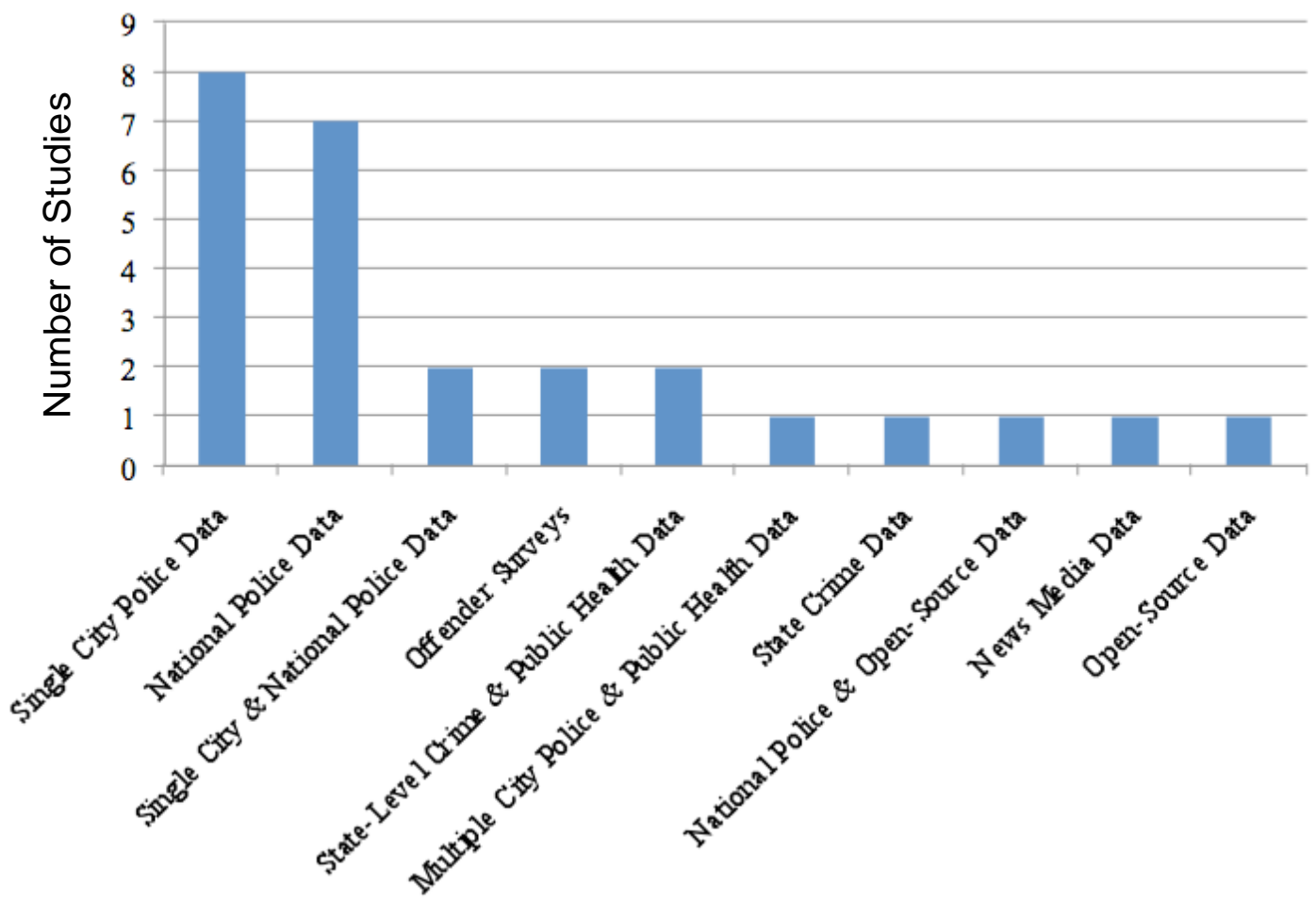

Figure 1: Data Sources Used to Study Homicide Events in Homicide Studies, 2007-2011 ( $n=26$.

exploratory analysis of anti-homeless homicide. Finally, implications for advancing the study of rare forms of lethal violence using open-source crime data are discussed.

\section{OBSTACLES TO STUDYING BIAS HOMICIDE}

Despite the need to further understand the nature of bias homicide, a number of methodological obstacles have stunted empirical research on this topic. To illustrate the most commonly used data sources, Figure 1 considers all quantitative studies of homicide published in Homicide Studies, ${ }^{2}$ a well-established outlet for homicide research, between 2007 and 2011. It is clear that official crime data sources have been by far the most relied upon sources of data whether from national crime data sources or from local law enforcement agencies.

While official data sources like the Uniform Crime Reports-Hate Crime Statistics or the FBl's National Incident Based Reporting System (NIBRS) attempt to provide national-level data on bias crimes, these data sources are not yet able to adequately inform us about the extent and nature of bias homicide in the United

\footnotetext{
${ }^{2}$ While homicide research is published in various social science journals, Homicide Studies was selected because the outlet has a topical focus on criminal homicide and remains a popular outlet for homicide research. Nevertheless, the findings shown in Figure 1 should not be considered representative of all homicide research published during this time frame (20072011).
}

States. Whereas traditional data sources used in homicide research more generally, such as the Uniform Crime Reports-Supplementary Homicide Report (SHR), have advanced knowledge about the causes and patterns of homicide thus far, it is often impossible to identify cases of lethal violence targeting minority groups from such sources. Even if it were possible to identify such cases, important information about victims, offenders, and situational characteristics would remain unavailable. In effect, homicide researchers choosing to rely on national crime data sources are inevitably restricted by the data law enforcement agencies choose to collect. Sources of official crime data, such as the SHR, include information on offenders' race, age, and sex. What is missing, however, are important offender details, including information about prior arrests. The same is true of homicide victims. For instance, theoretically important variables measuring victims' deviant behaviors (e.g., drug and alcohol abuse), which have begun to contribute to the likelihood of victimization, are not included.

Some scholars have attempted to circumvent the aforementioned methodological obstacles by relying on law enforcement agency-specific data. An advantage to utilizing police records directly from police agencies is the availability of in-depth accounts of specific homicide events that allow for the examination of less commonly 
occurring homicide types. In other words, researchers are not restricted by the homicide variables available from traditional crime data sources. In the past, several homicide researchers have successfully relied upon homicide detective records to substantially advance knowledge about certain types of lethal violence. Some recent examples include the work of Martinez (e.g., Martinez, Stowell, \& Cancino, 2008) who was granted access to several southwestern municipal police departments in order to examine Latino homicide victimization, as well as, Pizarro (e.g., Pizarro \& McGloin, 2006) who has relied on detective records to study gang homicide in Newark, New Jersey.

Unfortunately, there are also obstacles to studying bias homicide with agency-level police data. One obstacle is that by focusing on agency records from one or several geographically isolated police departments, the likelihood of some rare forms of homicide occurring is significantly reduced. Some jurisdictions, for instance, may only experience a single homicide of interest to the researcher for a set period of time. In effect, attaining representative data on a particular type of rare homicide may not be possible without gaining access to multiple police agencies across the country over long periods of time. Another obstacle to relying on agency-specific law enforcement data for studying bias homicide is gaining initial access to police department records. Researchers may face challenges in accessing police records depending on the nature of the existing relationships between police agencies and specific researchers, as well as, formal policies toward the use of crime data for academic research. Even with access to confidential police records, police agencies may have strict regulations on the types of information that can be accessed and may prohibit the duplication of police reports.

In contrast to national and local agency police data, advocacy groups for minority populations may currently provide the best assessment of serious violence against these groups in the United States. For example, the National Coalition for the Homeless (NCH) has provided annual reports for the last decade chronicling crimes against homeless persons, including homicide events, based on a number of sources (e.g., media reports). While useful for anecdotally demonstrating the severity of the anti-homeless crime problem, drawing an accurate depiction of the extent and nature of anti-homeless violence from these reports presents its own challenges. In particular, the anti-homeless violent crimes chronicled in advocacy group reports can vary greatly as to how much is known about the motivational circumstances. Consequently, many of these crimes included in annual chronologies may have very little to do with offenders' prejudices against victims. Including anti-homeless crimes motivated by discriminatory selection of victims with more routine crimes in chronologies of antihomeless violence may cloud a comprehensive understanding of the specific extent and nature of discriminatory violence against the homeless population.

In sum, most studies of homicide have relied on traditional crime data sources that often have not permitted the identification of rare homicide forms. Consequently, there has been very little research specifically on rare forms of homicide targeting social minority groups (see for exception Gruenewald, 2011; 2012) and no study has directly examined the topic of anti-homeless homicide to date. This is an important gap in the extant research on novel forms of lethal violence. Fortunately, researchers can utilize alternative methods to systematically study rare forms of homicide. Below, a research approach based on open-source data to study bias homicide is presented.

\section{ADVANTAGES AND DISADVANTAGES OF OPEN- SOURCE HOMICIDE DATA}

This paper suggests that currently the most suitable research approach for empirically examining the nature of bias homicide is through the collection of opensource data, or event-level data from sources including victim-advocacy chronology reports, court documents, and relevant news media articles. While open-source data have to date not been used to study routine crimes, some scholars have increasingly relied upon open-source data to build event-level databases on terrorist violence (LaFree \& Dugan, 2004). Examples of open-source terrorism databases include the Global Terrorism Database (GTD) (LaFree \& Dugan, 2007) and the International Terrorism: Attributes of Terrorist Events (ITERATE) database (Endler \& Sandler, 2006). These data sources have been used to significantly advance knowledge about international terrorism and to inform both theory and policy responses to terrorism violence. Another open-source database known as the Extremist Crime Database (ECDB) focuses exclusively on crimes committed by domestic extremists in the United States (Freilich, Chermak, Belli, Gruenewald, \& Parkin, 2014). Data from the ECDB have been utilized to examine various crimes, including homicide events 
committed by known far-right extremists (Gruenewald, 2011). ${ }^{3}$

Open-source data can similarly benefit the criminological study of rare forms of lethal violence not associated with political terrorism, including bias homicide. By relying on open-source data, it is possible to move beyond those variables that are available in traditional sources of crime data. From news media sources, for example, it is often possible to gather useful information regarding bias homicide offenders' motivations and basic demographic information. Relevant offender information, such as prior arrests, is also frequently available. Also important, open-source data allow researchers to track homicide offenders as they progress through the adjudicatory stages of the criminal justice system. Therefore, as is often the case, it is possible to attain media accounts of homicide offenders' arrests, trials, and sentencing hearings. As for situational variables, media accounts frequently provide details of fatal attacks, including the weapons used, number of participants, and the relationship between victim and offender. Other types of opensource materials, such as court documents, provide facts of the case and important legal and procedural details of bias homicide cases. In addition, advocacy group chronologies provide publicly-available annual reports on particular types of bias-motivated violence which often include brief narratives of lethal attacks. These narratives provide the names of homicide victims and offenders when they are known. Being able to identify homicide participants by name allows researchers to collect various forms of open-source information on rare homicide occurrences, such as those targeting minority populations.

Open-source data collection may also be more feasible compared to collecting police agency-level data. Obstacles to collecting police homicide data, such as gaining access to police agencies and detectives' files, can be avoided. In this way, open-source homicide data can save researchers substantial amounts of time and money. Relying on open-source homicide data also facilitates qualitative exploration of bias homicide events. For example, from select sources, such as available court documents, researchers can produce detailed narratives of bias

\footnotetext{
${ }^{3}$ In addition to violent crimes committed by the far-right, the ECDB also maintains data on property crimes, violent crimes, and financial crimes committed by eco-terrorists, animal rights extremists, and Al-Qaeda-inspired
} lone wolves in the United States. homicide situations. Qualitative analyses of rarely explored bias homicide events can lead to nuanced insights into the ways that fatal transactions transpire.

Open-source data on criminal events, however, are not without their own limitations. One potential issue with open-source data on rare forms of homicide is the lack of information in publicly-available sources, such as news media articles, for some crimes (LaFree et al., 2006; Noble, 2004). Fortunately, because of the relative seriousness of homicide there is typically information available from a variety of open-sources for each occurrence. Through the use of multiple sources, it is also possible to triangulate the information gathered for various homicide characteristics. Triangulating criminal events data can serve as a check for reliability of information across multiple publicly-available data sources.

Misinformation may also be a problem as the result of particular biases inherent in the originators of the data or due to unintentional errors (LaFree et al., 2006). There are ways to reduce the possible effects of misinformation on the quality of open-source data. For instance, it is possible to assess the historical accuracy of a particular data source by examining its past coverage of other relevant issues. It may also be possible to compare coverage of a particular event to the coverage of other known reliable sources of data (Noble, 2004). By doing so, it becomes possible for researchers to develop a working list of "trusted" sources of open-source data.

The remainder of this study demonstrates how open-source data can be used to study one form of rarely occurring lethal violence in the United States, anti-homeless homicide. The next section presents an approach to collecting open-source data on these homicides. Within this discussion, the importance of developing concrete criteria for the inclusion of antihomeless homicides is highlighted. What types of homicides are included in the final sample is discussed and examples of homicide cases that were excluded for various reasons are provided. Following a discussion of the method, exploratory findings on a set of known anti-homeless homicides are presented.

\section{VIOLENCE AGAINST HOMELESS PERSONS}

Violence against the homeless population has been referred to with various names, including "wilding" (McKinley, 1990) and, more recently, "bum stomping" 
(Klein, 2003). ${ }^{4}$ Advocacy groups for the homeless population have claimed that anti-homeless bias crime is increasing and outnumber all other types of officiallyreported bias crimes (National Coalition for the Homeless, 2012). Anecdotal evidence also suggests that violence against homeless persons can be especially brutal and entails stories of victims being beaten with bats, repeatedly stabbed, and set aflame. Despite the extreme nature of this type of crime, limited attention has been paid to violence against homeless persons by criminologists. Moreover, the number of existing studies on this type of violence have largely ignored the most serious incarnation of violence targeting this vulnerable population.

Violence that discriminately targets homeless persons has recently reached the national policy agenda in part due to advocacy groups reporting substantial increases in homeless victimization $(\mathrm{NCH}$, 2010). For a number of years, federal lawmakers have unsuccessfully attempted to pass The Hate Crimes Against the Homeless Statistics Act in an attempt to add victims of anti-homeless violence to the list of federally-protected victim groups and facilitate the collection of official data on this crime type (see Lichtblau, 2009). The inclusion of homeless persons as a protected victim group remains controversial. Critics have suggested that violence against homeless persons is a rare problem and overstated by advocates of bias crime laws (Senate Judiciary Subcommittee on Crime and Drugs, 2010). Similarly, others have suggested that because homelessness is a temporary (or even chosen) status adding homeless victims to federal bias crime protections would dilute the effectiveness of existing laws (see $\mathrm{NCH}, 2012$ ). Nevertheless, some states (e.g., Florida) have recently extended bias crime law protections to the homeless population largely as response to increasing antihomeless violence and a handful of high-profile cases (Eversley, 2010; Lichtblau, 2009).

The vulnerability of the homeless population is one reason that this topic is worthy of scholarly consideration. Homeless persons live unprotected lives and are disproportionately more likely to have to be exposed to a wide range of mental and physical distress (LaGory, Ritchey, \& Mullis, 1990). Prior experiences with traumatic events, abuse, among the homeless population (North, Smith, \& Spitznagel, 1994). Homeless youth are also more likely

${ }^{4}$ In the early 2000s, filmmakers of the notorious "bumfights" videos taped homeless persons fighting and partaking in other dangerous stunts. After attracting a substantial audience, investigative media reports and lawsuits against the filmmakers eventually led to the filmmakers agreeing not to make any more videos (Perry, 2006). to have come from abusive family backgrounds and have prior victimization experiences compared to homeless adults (Whitbeck \& Simons, 1993). On the streets, homeless persons operate daily within riskfilled and unpredictable environments that present increased opportunities for criminal victimization. Scholars have suggested that homeless persons perceive victimization as yet another obstacle to face among their many daily challenges (Fitzpatrick, LaGory, \& Ritchey, 1999; North et al., 1993).

A limited number of geographically-focused studies have explored the nature of criminal victimization among the homeless population (Cohen \& Sokolovsky, 1989; D'Ercole \& Struening, 1990; Fitzpatrick, LaGory, \& Ritchey, 1993; Goodman, Dutton, \& Harris, 1997; Kipke et al., 1997; North et al., 1994; Whitbeck \& Simons, 1993). While this research has generally found an elevated incidence rate of criminal victimization among homeless persons, a more recent study based on a national sample of the homeless population in the United States revealed that most homeless victims actually have multiple types of illegal acts committed against them, including theft and a range of violent crimes (Lee \& Shrock, 2005). Moreover, Lee and Schrock (2005) demonstrated that antecedent variables, including disaffiliation, prior trauma, and health problems, only increased the likelihood of homeless victimization. Lee and Schrock (2005) also found that victimization experiences were not homogenous across victim types. Homeless males and those receiving some form of income, for instance, were shown to be more likely to be victimized.

While some research has found that homicide is a relatively common cause of death for homeless men in some cities (e.g., Hwang, Orav, O'Connell, et al., 1997), to date prior research on violence against homeless persons has focused primarily on non-fatal forms of victimization. Some homeless advocacy groups, such as the National Coalition for the Homeless $(\mathrm{NCH})$, have suggested that violence against homeless persons is proportionately more likely to end in murder compared to other types of bias-motivated violence (Stateman, 2008). Although relatively rare in comparison to all violent crime, homicides are patterned and tend to follow scripts that involve usual suspect and victim types that typically interact within similar situational contexts. Decker (1993) and others have suggested that homicide tends to either be profitmotivated and committed by strangers (instrumental homicides) or dispute-related and committed by acquaintances or family members (expressive 
homicides) (see also Block \& Block, 1992). Prior research has noted, however, the importance of examining "deviant homicide," or homicide events that diverge significantly from normative expectations in order to broaden our understanding of variations in the social organization of lethal violent crime (Decker, 1996; Varano \& Cancinco, 2001). Homicide offending that discriminately targets the homeless population may be considered one form of "deviant homicide," as events consist largely of expressive violent attacks that are against homeless persons by strangers (most expressive attacks are committed by someone known to victims). In short, there remains a need to examine lethal attacks against homeless persons as one form of deviant homicide.

\section{OPEN-SOURCE DATA AND ANTI-HOMELESS HOMICIDE}

Data on anti-homeless homicides were extracted from an open-source database known as the Extremist Crime Database (ECDB). The ECDB identifies antihomeless homicides from a number of data sources. The first source included systematic searches of webbased LexisNexis News Index for relevant news media articles. This particular index made it possible to search a number of major national, regional, and local print news sources simultaneously for relevant antihomeless homicide news stories. Examples of key words used as search terms include "homeless" and "homicide" or "murder." Second, the ECDB identified anti-homeless homicide events from a number of advocacy groups that maintain chronologies of suspected bias crimes and crimes against vulnerable populations. In addition to chronologies from prominent organizations, such as the Southern Poverty Law Center (SPLC) and the Anti-Defamation League (ADL), the most heavily relied upon source for information on anti-homeless homicides was the National Coalition for the Homeless $(\mathrm{NCH})$ annual reports. ${ }^{5}$

\section{Anti-Homeless Homicide}

Based on these sources, a sampling frame was created that included all identified homicide cases involving homeless victims in the United States (excluding Puerto Rico) between 1999 and 2009. A decision was made to exclude anti-homeless homicides for which the identities of the homicide offenders were not known. Although advocacy groups, media sources, or others may have speculated that

\footnotetext{
${ }^{5}$ Reports can be found at http://www.nationalhomeless.org/projects/hatecrimes. html
}

victims were targeted because of offenders' biases toward the homeless population, there was too often insufficient indicators of discriminate victim selection in cases of unknown offenders to include such cases. No attempt was made to assess offenders' level of "hatred" for their victims. Instead, incidents were determined to be bias attacks in the current study through evidence that offenders discriminately selected victims based on their homeless status.

To evaluate discriminatory selection, a predetermined set of bias indicators, or indicators of offenders' discriminatory selection decisions, was applied to the remaining cases (see Table 1). One of the most prominent indicators of offenders' discriminate selection was the direct admission from homicide offenders. Direct admissions from offenders indicating that victims were selected because of their homeless status came in a variety of forms, including formal admissions during legal adjudication and informal admissions to others (e.g., friend, family members). Indirect admissions also included taunting victims and the use of derogatory remarks related to victims' homeless statuses before, during, and following fatal attacks. Another indicator of discriminatory selection of homeless victims included evidence that homicides transpired in response to behaviors associated with homelessness. The most common example of this type of victims' behavior was panhandling by victims. Finally, prior victimization of the homeless community also served as an indicator of discriminate victim selection. In some cases, for instance, homeless homicide victims were the direct recipients of antihomeless violence shortly before they were killed. In other cases, anti-homeless homicides were a part of a spree of violent attacks on homeless persons in the proximate area.

Cases were excluded from the study when there was a lack of concrete evidence that victims were selected based on their homeless status. Although many homicides occurred in locations known for being places frequented by homeless persons, reasons for which they were targeted often remained unclear. In several instances, there was simply not enough information known about the offender or the offender's reason for specifically targeting homeless victims. In addition, some homicide cases were excluded from the sample because they were perpetrated by offenders who were also homeless. Many of these excluded homicides occurred as the result of mundane arguments and related altercations. Other disputerelated homicides that occurred between homeless 
Table 1: Indicators of Anti-Homeless Homicide Inclusion and Exclusion

\begin{tabular}{|l|l|}
\hline Anti-Homeless Homicide Bias Indicators & $\begin{array}{l}\text { Reasons to Exclude Homicide Cases Involving Homeless } \\
\text { Victims }\end{array}$ \\
\hline \hline 1. Offender admission of bias & 1. Offender not identified \\
\hline $\begin{array}{l}\text { 2. Verbal taunting or derogatory remarks associated with homeless status } \\
\text { 3. Attack directly followed behavior associated with homelessness (e.g., } \\
\text { panhandling or other solicitation of money) }\end{array}$ & $\begin{array}{l}\text { 3. Homicide event the result of disputes unrelated to homeless } \\
\text { status }\end{array}$ \\
\hline $\begin{array}{l}\text { 4. Prior non-lethal attack on victim or another homeless person in } \\
\text { proximate area }\end{array}$ & \\
\hline 5. Prior anti-homeless victimization specifically by homicide offender & \\
\hline
\end{tabular}

victims and non-homeless perpetrators were also excluded.

\section{Open-Source Data Collection}

Once anti-homeless homicides were selected for inclusion, open-source information was systematically collected on each case. To gather all available opensource information, over twenty web-based search engines were searched (list available from author). Information about each anti-homeless homicide came in the forms of court documents, police agency briefs, advocacy group reports, news media articles, and a scattering of other web-based documents. While all homicide case searches resulted in some form of attainable information, many cases resulted in substantial amounts of information due to the extraordinary circumstances and high-profile status of these novel crimes.

Once all open-source data were collected, each homicide case was coded for a number of relevant incident, suspect, and victim-level variables in an electronic codebook (see Tables 2 and 3). Some of the homicide variables collected mirrored variables collected by national police data sources. Incident-level variables included weapon type, number of homicide participants, and victim-and offender relationship. For suspects and victims, other variables were collected, including basic demographic information. One of the advantages of the ECDB's open-source homicide data is that it was possible to also collect new types of information, such as information on participants' prior arrests and alcohol and drug use, which are excluded from other official homicide databases. This information provides additional insight into the nature of this rare form of lethal violence. The following section presents the findings from an exploratory analysis of antihomeless homicide incidents $(n=45)$, suspects $(n=96)$, and victims $(n=49)$.

\section{FINDINGS}

This study presents the first known description of participant and incident-level characteristics of antihomeless homicide events in the United States. The number of events reflects the relative infrequency of this type of violence. Therefore, the reported distributions may be sensitive to subtle differences across homicide characteristics. The novelty of these lethal attacks, however, is also one reason that antihomeless homicide events become high-profile cases and why alternative research approaches and methodological innovations are necessary to study them. Below, findings on homicide characteristics are followed by a description of anti-homeless homicide suspects and victims.

Several interesting incident-level anti-homeless homicide characteristics deserve mention. As shown in Table 2, anti-homeless homicides occurred in every year during the specified time frame. The year with the highest proportion of events during the time frame for this study was 2007 (20\%). In contrast, the year 2003 saw the lowest proportion of known lethal antihomeless attacks. The locations of homicide events varied across a number of outdoor settings. The most prominent location for homicide events to take place was a public park (22.2\%).

The next most common locations for homicides included streets and under bridges or highway overpasses. These attacks generally occurred after dark when victims had settled in for the night. Many victims were awakened by the attackers prior to the fatal attacks. What is interesting about the locations of these attacks is the relative infrequency of attacks that occurred at homeless encampments. One explanation for this finding is that homeless encampments only exist in some cities-particularly larger ones. On the other hand, it may also be that offenders are less likely to attack victims in the presence of other homeless 
Table 2: Anti-Homeless Characteristics $(n=45)$

\begin{tabular}{|c|c|c|}
\hline & $\mathbf{N}$ & Percentage \\
\hline \multicolumn{3}{|l|}{ Year } \\
\hline 1999 & 2 & 4.4 \\
\hline 2000 & 2 & 4.4 \\
\hline 2001 & 5 & 11.1 \\
\hline 2002 & 5 & 11.1 \\
\hline 2003 & 1 & 2.2 \\
\hline 2004 & 3 & 6.7 \\
\hline 2005 & 5 & 11.1 \\
\hline 2006 & 6 & 13.3 \\
\hline 2007 & 9 & 20.0 \\
\hline 2008 & 3 & 6.7 \\
\hline 2009 & 4 & 8.9 \\
\hline \multicolumn{3}{|l|}{ Location } \\
\hline Alley & 4 & 8.9 \\
\hline Bridge & 7 & 15.6 \\
\hline Homeless Encampment & 3 & 6.7 \\
\hline Outside of Business & 4 & 8.9 \\
\hline Outside Homeless Outreach & 2 & 4.4 \\
\hline Park & 10 & 22.2 \\
\hline Railroad Tracks & 1 & 2.2 \\
\hline Sidewalk & 2 & 4.4 \\
\hline Street & 7 & 15.6 \\
\hline Vacant Lot/Building & 2 & 4.4 \\
\hline Wooded Area & 3 & 6.7 \\
\hline Multiple Suspects & 35 & 77.8 \\
\hline Multiple Victims (Deaths) & 3 & 6.7 \\
\hline \multicolumn{3}{|l|}{ Primary Weapon } \\
\hline Blunt Object & 23 & 51.1 \\
\hline Bodily Weapon (Only) & 12 & 26.7 \\
\hline Knife & 2 & 4.4 \\
\hline Firearm & 4 & 8.9 \\
\hline Burned to Death & 4 & 8.9 \\
\hline \multicolumn{3}{|l|}{ Region } \\
\hline Northeast & 7 & 15.6 \\
\hline West & 16 & 35.6 \\
\hline South & 14 & 31.1 \\
\hline Midwest & 8 & 17.8 \\
\hline Population over 200,000 & 28 & 62.2 \\
\hline
\end{tabular}

\$Percentages may not equal 100 due to rounding.

persons. It follows that offenders may be more likely to select homeless persons to attack when they are found alone and considered more vulnerable.
Approximately 77 percent of anti-homeless homicide events were perpetrated by multiple suspects. This is remarkable given that multiple suspect homicides are relatively rare. For example, fewer than 15 percent of all homicides in the United States involved multiple suspects in 2010 (FBI, 2011). Furthermore, Table 2 reveals that a small percentage $(6.7 \%)$ of anti-homeless homicides involved multiple victim deaths. It is clear from these findings that offenders generally preferred to victimize homeless in small groups and, moreover, offenders preferred to attack solitary victims outside the purview of others.

Another unique circumstance of anti-homeless homicide was the weapon choices of offenders. The findings in Table 2 reveal the primary weapon used by the offender to cause death to the victim. This study showed that over 50 percent of all anti-homeless homicides in this study were committed primarily with blunt objects. This clearly demonstrates one way antihomeless homicide is unique from traditional violence, as homicides are typically committed with firearms in the United States (FBI, 2011). Remarkably, the homeless victims included in this study were just as likely to be shot to death as being set afire and burned to death. It appears that the most efficient killing of victims was rarely a concern to offenders. While some planned attacks used objects, such as baseball bats owned by the offenders, other attacks involved blunt objects available at the time of the lethal attack (e.g., metal pipes, lumber, sticks, etc.). The next most commonly used weapon by offenders was bodily weapons (e.g., hands, feet, etc.). Most cases included bodily weapons to some degree; however, approximately 27 percent of anti-homeless homicides were committed with bodily weapons and without the use of other types of weapons. In these cases, offenders often took turns brutally kicking, stomping, and punching victims.

This study also considered the geographic and demographic context in which anti-homeless homicides occurred. Findings reveal that the majority of lethal attacks against homeless persons occurred in the southern and western regions of the United States. In the South, the majority of anti-homeless attacks occurred in Florida. This finding is not surprising as national advocates for the homeless have pointed to Florida as recently having increasing homeless populations and elevated instances of anti-homeless violence (Gibson, 2012). In response, Florida is currently one of the few states that have added homeless victims to existing state-level bias crime 
protections (Gibson, 2012; $\mathrm{NCH}, 2012$ ). The state that led the West in lethal anti-homeless attacks was California, a state that has also yet to classify antihomeless violence as a bias crime. While conventional wisdom would suggest that anti-homeless homicide is primarily an urban phenomenon, this study found that nearly 40 percent of cases occurred in cities and towns with populations less than 200,000 people. $^{6}$ Undoubtedly, the largest cities lead in overall antihomeless violence; nonetheless, a substantial portion of the most serious form of anti-homeless violence occurred outside of these urban centers.

In addition to incident-level homicide characteristics, there are a number of interesting findings for the participants of anti-homeless homicides (see Table 3). Not surprising, nearly all of the offenders were male. A more notable finding regarding the race of homicide suspects is that nearly 50 percent of anti-homeless homicide offenders were Black, which is nearly identical to the overall representation of Black homicide offenders in the United States (FBI, 2011). This is interesting as conventional wisdom holds that bias crimes against other social minority groups (e.g., racial bias crimes, anti-sexual orientation bias crimes) are typically perpetrated by White males. Research is needed to comparatively examine offender backgrounds (e.g., involvement in gangs) across antihomeless and other bias homicide types to better understand differences in the racial makeup of offenders.

Also important, Table 3 reveals that the average anti-homeless homicide offender was a teenager (19.1 years old). For homicides involving multiple offenders, juvenile offenders often co-offended with slightly older adults.

One advantage of relying on the ECDB for antihomeless homicide data is that additional information regarding offenders' behavior is available. Table 3 shows that there was evidence in over 30 percent of anti-homeless homicide cases that offenders consumed alcohol prior to attacking victims. This is curious as the typical anti-homeless homicide offender was under the legal drinking age. Although less common, there was also evidence that illegal drug use was a precursor factor to several anti-homeless homicides (17.4\%). Illegal consumption of alcohol and use of drugs may tell us something about the general lifestyles of anti-homeless homicide offenders and

\footnotetext{
${ }^{6}$ Measures are based on 2009 Census estimates of the cities or towns in which
} homicide events occurred.
Table 3: Anti-Homeless Homicide Offender and Victim Characteristics

\begin{tabular}{|c|c|c|}
\hline Offender Characteristics (N=96) & $\mathbf{N}$ & Percentage ₹ \\
\hline \multicolumn{3}{|l|}{ Race } \\
\hline White & 36 & 40.4 \\
\hline Black & 44 & 49.4 \\
\hline Hispanic & 7 & 7.9 \\
\hline Native American & 2 & 2.2 \\
\hline Suspect Male & 95 & 99.0 \\
\hline Age & 84 & 19.1 (avg.) $\ddagger \neq$ \\
\hline Evidence of Alcohol Use & 86 & 33.7 \\
\hline Evidence of Drug Use & 86 & 17.4 \\
\hline Evidence of Prior Arrests & 86 & 38.4 \\
\hline \multicolumn{3}{|l|}{ Victim Characteristics ( $\mathrm{N}=49$ ) } \\
\hline \multicolumn{3}{|l|}{ Race } \\
\hline White & 22 & 55.0 \\
\hline Black & 13 & 32.5 \\
\hline Hispanic & 5 & 12.5 \\
\hline Native American & 0 & 0.0 \\
\hline Suspect Male & 47 & 95.9 \\
\hline Age & 49 & 49.7 (avg.) $\nRightarrow \neq$ \\
\hline Evidence of Alcohol Use & 19 & 43.2 \\
\hline Evidence of Drug Use & 7 & 15.6 \\
\hline Evidence of Prior Arrests & 5 & 10.9 \\
\hline
\end{tabular}

† Percentages may not equal 100 due to rounding.

$\sharp$ A Age of offender and victim are represented by mean statistics rather than percentages.

about some of the contributing factors precipitating many of these lethal attacks. Another important finding, approximately 38 percent of offenders had been arrested prior to participation in an anti-homeless homicide. Likely undercounting the prior arrests of offenders due to the unavailability of information from juvenile arrests records, the current study begins to paint a picture of anti-homeless homicide offenders as being made up of informal groups of young males (usually Black) who often participated in other deviant activities.

The current study also provides findings for a number of anti-homeless homicide victim characteristics. The first victim characteristic shown in Table $\mathbf{3}$ is race or ethnicity of homeless victims. Interestingly, victims of anti-homeless homicides were proportionately more likely to be White than offenders. This is important as Blacks are more likely than Whites to be victims of homicide in the United States overall (FBI, 2011). In other words, while the racial makeup of anti-homeless offenders closely resembles that of the 
overall homicide offender, the same is not true of victims. In addition, while the vast majority of victims were male, as expected, the increased age of antihomeless homicide victims was more notable. Indeed, the average age of homeless victims was nearly 50 years of age. This is remarkable when contrasted with the especially young average age of offenders.

The proportions of cases for which there was evidence that victims were under the influence of drugs $(15.6 \%)$ or alcohol $(43.2 \%)$ during the homicidal attacks was somewhat similar to the proportion of offenders under the influence. Again, likely representing an undercounting of substance abuse at the time of the attack, findings reveal that alcohol and drugs played a substantial role in the lethal victimization of homeless persons. Evidence of victims' prior arrests, however, was minimal (10.9\%), especially when compared to homicide offenders.

\section{DISCUSSION}

This study is the first known empirical exploration specifically on the nature of anti-homeless homicide events. Relying on open-source data from the ECDB, a number of anti-homeless homicide event characteristics occurring in the United States from 1999 to 2009 were examined. The exploratory analysis conducted for this study resulted in a number of notable findings. Many of these findings gave credence to conventional wisdom about violence against homeless persons, while others were certainly counterintuitive. In particular, findings revealed interesting differences between the demographic makeup of anti-homeless homicide victims and offenders. Homicide offenders were proportionately younger and slightly more likely to be Black. In contrast, victims of these homicides were proportionately older and proportionately more likely to be White. Therefore, anti-homeless homicides often consisted of interracial offender-victim combinations. Another notable contrast was in offender and victim ages. While it appears that anti-homeless offending is primarily an issue of juvenile crime, the victims of these lethal attacks were older than the typical homicide victim. This is possibly due in part to the increased age of the homeless population overall. The question of whether older homeless victims are more likely to be targeted than the young, however, could not be answered with this preliminary analysis. Regardless, the victim-offender age differences run counter to the typical homicide profile and reiterate the uniqueness of fatal anti-homeless attacks.
Other findings contribute to the portrayal of antihomeless homicide as an especially sinister form of violence. Commonly, attacks involved multiple young offenders, often intoxicated and seeking out solitary homeless persons to victimize. These attacks were most always excessively brutal and rarely involved the use of firearms. Instead, most involved a lethal combination of available blunt objects and bodily weapons (i.e., stomping).

Changes in social welfare policy, education, and law enforcement practices may be able to alleviate or alter the conditions leading to anti-homeless homicide. Homelessness is often a solitary lifestyle by "choice," and the ability to travel the road alone may be one of the only desirable aspects of their homelessness. Nonetheless, increasing the availability of homeless shelters and outreach centers would lead to increases in the number of capable guardians and decreases in the numbers of suitable targets. More strictly enforcing local ordinances regarding the use of public space may also be advisable options for reducing the risk of violence. As for motivated offenders, there may be a number of options that align with other educational programs to curb juvenile crime and deviance. More specific to the victimization of homeless by juveniles, educational programs are needed to inform youth about the conditions which can lead to homelessness and the often thin line that separates "us" and "them." By doing so, potential offenders may be less inclined to target members of society's most vulnerable.

This study made a case for the relevance of antihomeless homicide as an important topic of inquiry for criminologists. The homeless population is targeted for violence because they are considered "easy prey," and viewed as weak and unlikely to put up a fight. Homeless victims become even more vulnerable targets when they are outnumbered by offenders, as is typically the case. Homeless persons are painfully aware of the risk of violent victimization that comes with their lifestyle and perceptions of risk are only heightened by violent crimes committed against other homeless persons (Fitzpatrick et al., 1999).

Despite failed attempts to add homeless victims to federal bias crime protections and public attention to a handful of relatively high-profile cases, violence against the homeless population has gone largely unnoticed by the public and policymakers, as well as, criminologists. Why has there been such a dearth of research on violence against this minority population? One explanation is that due to their relative infrequency, 
scholars have yet to deem the topic of anti-homeless violence warranting of empirical exploration. The same argument, however, has been made of other types of bias crime and rare forms of violence, including terrorism. Terrorism research in the United States, however, has received considerable scholarly attention by criminologists and others (even before the September $11^{\text {th }}$ terrorist attacks in New York City, Washington D.C., and Pennsylvania). Importantly, the relative frequency of violent events is not the only (or necessarily the most important) factor influencing the social relevance of a particular type of crime. Violent crimes against some victim groups, though rare, have potential to shape attitudes and fear of crime for targeted communities and the broader communities in which these crimes occur. For this reason, crime scholars must overcome their reluctance to studying novel forms of violent crime. Instead, there should be an effort to develop innovative ways to study these crimes as, in some ways, the study of rare forms of violent crime may be just as important to theoretical and policy development as studying the most commonly occurring types of violent crime.

In the past, a lack of available data has kept many scholars from studying anti-homeless homicide. In response to the unavailability of official homicide data, the current study demonstrated one approach to utilizing open-source data. More specifically, this study relied on the ECDB which systematically gathers information about extremist homicide cases from publicly-available sources, such as advocacy group reports and print news articles. Likely due in part to the seriousness and novelty of these crimes, there was ample information on most anti-homeless homicide events and the amount of missing values for cases was minimal. The utility of open-source databases for studying novel forms of homicide should not be understated. Not only was this study able to provide data for the most studied elements of homicide events, but the open-source database also extended what could be known about victims and offenders from criminal events data by including information on the deviant lifestyle of homicide participants. As such, alternative open-source databases like the ECDB can lead to important advancements on what is known about previously understudied forms of serious violence. In this way, the current study champions Maltz's (1994, p.457) argument that:

"...we should consider the possibility that the data we currently collect and the categories we currently use may be lacking, and attempt to collect different kinds of data, using more relevant categories, recognizing full well that this may require the application of judgment on the part of the data collectors. We should also do more research into how we can extract data from the richer sources that are at our disposal, the narrative accounts that provide a much clearer picture of offenders, offenses, and communities than do the standard types of data that are used in criminological research."

Researchers, however, should continue to approach the collection of open-source data with caution. While there may be ample amounts of useful information on rare crimes that is publicly-available, it requires a detailed research plan and a substantial amount of resources to efficiently and carefully identify crimes of interest, develop strategies to collect data from multiple sources, and to attain the level of human resources needed to detail code complex criminal cases. It is also pertinent that decisions be made early in the research process regarding which cases will be included and excluded from the final sample based on transparent and objective criteria. While scholars should seek new sources of data for studying rare forms of homicide, it is only through well-crafted research designs and thoughtful methodologies that open-source data collection efforts will become more widely adopted as a useful alternative to traditional sources of homicide data.

\section{REFERENCES}

Cohen, C.I., \& Sokolovsky, J. (1989). Old men of the bowery: Strategies for survival among the Homeless. New York: Russell Sage Foundation.

Cooper, A., \& Smith, E.L. (2011). Homicide trends in the United States. Bureau of Justice Statistics. Retrieved on December 5, 2013 from http://www.bjs.gov/index.cfm?ty=pbdetail\&iid $=2221$

Decker, S.H. (1993). Exploring victim-offender relationships in homicide: The role of individuals and event characteristics. Justice Quarterly, 10, 585-612. http://dx.doi.org/10.1080/07418829300092031

Decker, S.H. (1996). Deviant homicide: A new look at the role of motives and victim- offender Relationships. Journal of Research in Crime and Delinquency, 33, 427-449. http://dx.doi.org/10.1177/0022427896033004003

D'Ercole, A., \& Struening, E. (1990). Victimization among homeless women: Implications for service delivery. Journal of Community Psychology, 18, 141-152. http://dx.doi.org/10.1002/1520-6629(199004)18:2<141::AIDJCOP2290180206>3.0.CO;2-O

Endler, W., \& Sandler, T. (2006). The political economy of terrorism. New York: Cambridge University Press.

Eversley, M. (2010). Homeless in Florida could get protection under hate crime law. USA Today, April 21. Retrieved on June 5, 2012 from http://content.usatoday.com/communities/ 
ondeadline/post/2010/04/homeless-in-florida- could-getprotection-under-hate-crime-law/1\#.T86LqFKvPyU

Federal Bureau of Investigation. (2011). Crime in the United States, 2010. Department of Justice. Retrieved on July 17, 2012 from http://www.fbi.gov/about-us/cjis/ucr/crime-in-the- u.s/ 2010/crime-in-the-u.s.-2010/tables/10shrtbl04.xls

Fitzpatrick, K.M., LaGory, M.E., \& Ritchey, F.J. (1993). Criminal victimization among the homeless. Justice Quarterly, 10(3), 353-368. http://dx.doi.org/10.1080/07418829300091881

Fitzpatrick, K.M., LaGory, M.E., \& Ritchey, F.JK. (1999). Dangerous places: Exposure to violence and its mental health consequences for the homeless. American Journal of Orthopsychiatry, 69(4), 438-447. http://dx.doi.org/10.1037/h0080392

Freilich, J.D., Chermak, S.M., Belli, R., Gruenewald, J., \& Parkin, W. (2014). Open source research and terrorism studies: Introducing the United States Extremist Crime Database (ECDB). Terrorism and Political Violence. http://dx.doi.org/10.1080/09546553.2012.713229

Gibson, W. (2012). Broward leads crackdown on violence against homeless. Sun Sentinel, July 10. Retrieved on July 31, 2012 from http://weblogs.sun- sentinel.com/news/politics/dcblog/ 2012/07/broward_leads_crackdown_on_vio.html

Goodman, Lisa A., Mary Ann Dutton, and Maxine Harris. 1997. "The Relationship Between Violence Dimensions and Symptom Severity Among Homeless, Mentally III Women." Journal of Traumatic Stress 10:51-70. http://dx.doi.org/10.1002/jts.2490100106

Gruenewald, J. (2012). Are anti-LGBT homicides unique? Journal of Interpersonal Violence, 27(18), 3601-3623. http://dx.doi.org/10.1177/0886260512462301

Gruenewald, J. (2011). A comparative examination of far-right extremist homicide events. Homicide Studies, 15, 177-203. http://dx.doi.org/10.1177/1088767911408029

Hwang, S.W., Orav, E.J., O'Connell, J.J., et al. (1997). Causes of death in homeless adults in Boston. Annals of Internal Medicine, 126, 625-628.

http://dx.doi.org/10.7326/0003-4819-126-8-199704150$\underline{00007}$

Klein, A. (2003). Third defendant found guilty in killing homeless man. The Baltimore Sun, Retrieved on June 5, 2012 from http://articles.baltimoresun.com/2003-11-26/news/03112600 68_1_waterbury-homeless-holle

Kipke, M. D., Simon, T.R., Montgomery, S.B. Unger, J.B., \& Iversen, E.F. (1997). Homeless youth and their exposure to and involvement in violence while living on the streets. Journal of Adolescent Health, 20, 360-367. http://dx.doi.org/10.1016/S1054-139X(97)00037-2

LaFree, G., \& Dugan, L. (2004). How does studying terrorism compare to studying crime? Sociology of Crime, Law and Deviance, 5, 53-74.

LaFree, G., \& Dugan, L. (2007). Introducing the Global Terrorism Database. Terrorism and Political Violence, 19, 181-204. http://dx.doi.org/10.1080/09546550701246817

Lee, B.A., Schreck, C.J. (2005). Danger on the streets: Marginality and victimization among homeless people. American Behavioral Scientist, 48, 1055-1081. http://dx.doi.org/10.1177/0002764204274200
Lichtblau, E. (2009). Attacks on homeless bring push on hate crime laws. The New York Times, August 7. Retrieved June 5, 2012 from http://www.nytimes.com/2009/08/08/us/08 homeless.html?pagewanted=all

Martinez, R., Jr., Stowell, J.R., \& Cancino, J.M. (2008). A tale of two border cities: Community context, ethnicity, and homicide. Social Science Quarterly, 89, 1-16. http://dx.doi.org/10.1111/j.1540-6237.2008.00518.x

McKinley, J.C., Jr. (1990). Wilding youth and homeless: A blood feud. The New York Times, November 3. Retrieved June 5, 2012 from http://www.nytimes.com/1990/11/03/nyregion/ wilding-youth-and-homeless-a-blood- feud.html?pagewanted $=$ all $\& \mathrm{src}=\mathrm{pm}$

Maltz, M.D. (1994). Deviating from the mean: The declining significance of significance. Journal of Research in Crime and Delinquency, 31(4), 434-463. http://dx.doi.org/10.1177/0022427894031004005

National Coalition for the Homeless. (2010). Hate crimes against the homeless: America's growing tide of violence. National Coalition for the Homeless. Retrieved on June 5, 2012 from http://www.nationalhomeless.org/publications/hatecrimes/hat ecrimes2009.pdf

National Coalition for the Homeless. (2012). Hate crimes against the homeless: An organizing manual for concerned citizens. National Coalition for the Homeless. Retrieved on June 5, 2012 from http://www.nationalhomeless.org/publications/ hatecrimes/hatecrimesmanual12.pdf

National Coalition for the Homeless. (2012). Hate crimes against the homeless. Violence hidden in plain view. National Coalition for the Homeless. Retrieved on June 5, 2012 from http://www.nationalhomeless.org/publications/hatecrimes/hat ecrimes2010.pdf

North, C.S., Smith, E.M., \& Spitznagel, E.L. (1994). Violence and the homeless: An epidemiologic study of victimization and aggression. Journal of Traumatic Stress, 7, 95-109. http://dx.doi.org/10.1002/its.2490070110

Perry, T. (2006). 'Bumfight' producers throw in the towel. The Los Angeles Times, April 7. Retrieved August 9, 2012 from http://articles.latimes.com/2006/apr/07/local/me-bums7

Pizarro, J.M., \& McGloin, J.M. (2006). Explaining gang homicides in Newark, NJ: Collective behavior or social disorganization. Journal of Criminal Justice, 34(2), 195- 207. http://dx.doi.org/10.1016/j.jcrimjus.2006.01.002

Senate Judiciary Subcommittee on Crime and Drugs. (2010). Crime against America's homeless: Is the violence growing? Congressional Documents and Publications. Retrieved on June 5, 2012 from http://www.judiciary.senate.gov/hearings/ hearing.cfm? $\mathrm{id}=\mathrm{e} 655 \mathrm{f} 9 \mathrm{e} 2809 \mathrm{e} 5476862 \mathrm{f} 735 \mathrm{da} 163 \mathrm{e} 08 \mathrm{e}$

Stateman, A. (2008). Violence against the homeless: Is It a Hate Crime? Time, October 22. Retrieved on July 27, 2012 from http://www.time.com/time/nation/article/0,8599,1852825,00.ht $\mathrm{ml}$

Varano, S.P., \& Cancino, J.M. (2001). An empirical analysis of deviant homicides in Chicago. Homicide Studies, 5(1), 5-29. http://dx.doi.org/10.1177/1088767901005001002

Whitbeck, L.B., \& Simons, R.L. (1993). A comparison of adaptive strategies and patterns of victimization among homeless adolescents and adults. Violence \& Victims, 8(2), 135-15.

\section{DOI: http://dx.doi.org/10.6000/1929-4409.2013.02.48}

(C) 2013 Jeffrey A. Gruenewald; Licensee Lifescience Global.

This is an open access article licensed under the terms of the Creative Commons Attribution Non-Commercial License (http://creativecommons.org/licenses/by-nc/3.0/) which permits unrestricted, non-commercial use, distribution and reproduction in any medium, provided the work is properly cited. 